\title{
Políticas públicas y enfoques diferenciales: aproximaciones desde la interculturalidad y la democracia radical
}

\author{
Public policies and Differential perspective: approaches since \\ interculturality and radical democracy \\ Andrés Francisco Olivar Rojas \\ Corporación Universitaria Minuto de Dios-uniminuto, \\ Sede Cundinamarca, Girardot, Colombia \\ Correo: aolivar@uniminuto.edu \\ ORCID: https://orcid.org/o000-0003-3504-0347 \\ ISSN-OI85-4259; e- ISSN: 2007-9I76 \\ DoI: http://dx.doi.org/I0.28928/ri/882020/aotI/olivarrojasa
}

\begin{abstract}
Resumen
El enfoque diferencial surge como estrategia de política pública destinada a la protección y reivindicación de derechos de las poblaciones históricamente afectadas por el conflicto armado en Colombia. Asimismo, el Estado colombiano se ha encargado de generar un numeroso conjunto de disposiciones jurídicas, que pretende ser la herramienta mediante la cual se satisfaga la protección de los derechos vulnerados en el contexto del conflicto armado. En ese sentido, el objetivo de este artículo es realizar un análisis crítico del concepto de políticas públicas con enfoque diferencial a partir de los conceptos de multiculturalidad, interculturalidad y democracia radical, teniendo en cuenta que las poblaciones objeto de políticas con enfoque diferencial son también aquellas que reclaman la profundización de la democracia y la ciudadanía, pues han sido asimiladas dentro del concepto universalista de la democracia liberal-representativa. De esta forma, el análisis político crítico parte de categorías como interculturalidad y democracia radical, que se emplearán como conceptos transversales para el análisis de políticas públicas con enfoque diferencial y para pensar en la oportunidad de proyectar el accionar de los sistemas políticos desde otras epistemologías, que partan de la diferencia y la no homogeneización.

Palabras clave: subalternidad, indígenas, LGBTI, pluralismo, hegemonía/antihegemonía.
\end{abstract}

\begin{abstract}
The Differential perspective rises up as a public policy strategy destined to the protection and rights reclaiming from historically isolated groups, affected by armed conflict in Colombia. Likewise, Colombian state has created a large number of legal regulation, which pretends to be a tool that satisfies protection of vulnerated rights in armed conflict context. In that sense, this paper aims to make an analysis of public policies from Differential perspective since concepts like multiculturalism, interculturality and radical democracy. Based on those concepts, the arguing towards to how public policies with differential perspective in Colombia normalize social and political exclusion of subordinated groups. The analysis is made according to the premise that populations target of Differential perspective policies also, are those which, claims the deepening of the democracy and citizenship, since they have been assimilated into the representative democracy universal concept. This way, political analysis begins from categories such as interculturality and radical democracy, that will be used as transversed concepts to make an analysis of public policies from Differential perspective and to think about the chance to plan the political systems actions from other epistemologies, that work from the difference and no homogenization.

Key words: Radical democracy, Interculturality, Multiculturalism, Hegemony/ anti-hegemony.
\end{abstract}

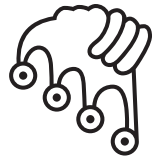

IZTAPALAPA

Agua sobre lajas 


\section{Introducción}

G eneralmente, el debate en torno al análisis, el diseño, la formulación y la implementación de políticas públicas se centra en su eficiencia y su eficacia, es decir, en el impacto o la incidencia de las acciones del sistema político para resolver problemas públicos. Sin embargo, tan importante como lo anterior es la elección de un marco de referencia que logre interpretar la realidad desde determinadas aproximaciones a ella.

En ese sentido, vale decir que la elección de un enfoque epistemológico para el análisis o la formulación de políticas suele ser un proceso que los hacedores de políticas en la actualidad soslayan, pues suele primar el enfoque técnico o tecnocrático, con la intención de aquello que Roth llama "abolir la política, poner fin a la lucha y a la confusión de la sociedad humana con una administración ordenada de las cosas, basada en el conocimiento objetivo" (Roth, 2014: 79), pretensión de los positivistas que hacen políticas en el vacío, sin tener en cuenta el contexto de la población receptora, sus demandas o necesidades. Dado que la formulación de políticas responde a criterios de costo-beneficio (impacto), se ignora la dimensión de politics en el diseño de políticas.

Por lo anterior, este artículo, de tipo teórico y documental, parte de una apuesta conceptual desde la cual las políticas públicas con enfoque diferencial, en su análisis, diseño, formulación e implementación, deben partir desde un enfoque epistemológico pospositivista, constructivista y crítico. Esto debido a que se parte del siguiente argumento: las poblaciones objeto de políticas con enfoque diferencial son también aquellas que, desde la interculturalidad, reclaman la profundización de la democracia y de la ciudadanía, pues han sido asimiladas dentro del concepto universalista de la democracia liberal-representativa.

Asimismo, vale aclarar que la intención de este artículo es la exposición argumentativa en torno del análisis de políticas públicas con enfoque diferencial en Colombia - reflejadas principalmente en disposiciones jurídicas - y la discusión teórica a partir de los conceptos de interculturalidad, multiculturalidad y democracia radical. Es un 
estudio documental que busca enriquecer el debate teórico sobre la relación entre políticas públicas e interculturalidad a la luz del estudio de algunos casos particulares en Colombia, referidos principalmente a la población indígena, la población LGBTI, el extractivismo y las herramientas democráticas disponibles para prevenir o detener prácticas que van en contra de poblaciones cuya noción del "desarrollo" es opuesta a la visión economicista del Estado colombiano y de sus clases dirigentes. En ese orden de ideas, se propone la siguiente estructura: primero, un desarrollo teórico basado en la relación polity-policy-politics y el vínculo entre el análisis de políticas públicas desde el enfoque epistemológico crítico-construccionista y los enfoques diferenciales; segundo, la relación entre los conceptos de interculturalidad y el Estado como dispositivo legitimador de la exclusión de minorías subalternizadas; tercero, las características jurídicas de las políticas públicas con enfoque diferencial; y cuarto, un análisis de la aplicación de las políticas con enfoque diferencial en casos particulares.

\section{Desarrollo teórico}

\section{Relación polity-policy-politics}

La implementación de políticas es un proceso íntimamente ligado a la lucha por el poder, es decir, que depende de la voluntad política de quienes ostentan la capacidad de decisión y acción. Esto, que puede sonar a obviedad, a veces es ignorado tanto por los hacedores de políticas como por la ciudadanía en general, pues se cree que se trata de un proceso meramente técnico-administrativo, de gestión presupuestal que se ajusta a criterios de eficiencia y eficacia, pero no se puede ignorar el contexto político, sus actores y sus agendas.

Roth hace referencia al bucle polity-politics-policy, que explica la interacción de tres elementos de cualquier sistema político, en el cual los dos primeros influyen en el tercero. Polity, o "el ámbito del gobierno en las sociedades humanas" (Roth, 20I4ः35), se refleja en los arreglos institucionales y las reglas de juego empleadas en un régimen político para garantizar el orden y la convivencia. Dichos arreglos institucionales pueden determinar si una forma de gobierno es democrática o antidemocrática, $y$ ello tendrá una incidencia determinante en la construcción de políticas públicas. Politics, por su lado, hace referencia al proceso mediante el cual se realiza la "actividad de organización y lucha por el control del poder" y policy, se entiende como los resultados, las decisiones y las acciones del sistema político para resolver problemas públicos, o la "designación de los propósitos y programas de las autoridades públicas". 
Podría afirmarse, entonces, que las políticas públicas son resultado de su interacción con las instituciones políticas, la forma de gobierno, las ideas políticas y las reglas de juego, elementos que dan forma a las políticas públicas.

\section{Figura I.}

Relación entre polity, policy y politics. Fuente: elaboración propia.

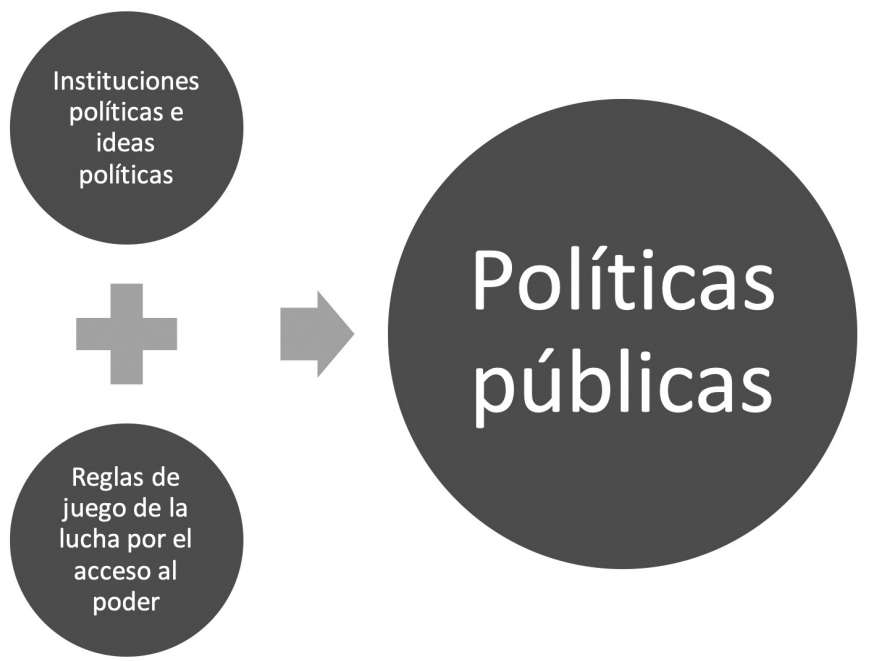

Por lo anterior, se entiende que las políticas públicas no pueden ni deben estar alejadas del contexto institucional e ideológico. Ahora, ¿̨cuál es el vínculo entre epistemología y políticas públicas?

Roth plantea una relación simbiótica entre los enfoques epistemológicos para el análisis de políticas y la aplicación de estas en un espacio y un tiempo determinados. Se plantea la siguiente analogía, simple pero ilustrativa: los enfoques epistemológicos son como el aire que respiramos: no lo vemos, no lo sentimos, pero son el soplo vital, pues sin ellos no hay un marco de referencia para aproximarse a una realidad, interpretarla e interpelarla. Dicho autor sugiere cuatro epistemologías: positivista, pospositivista, construccionista y crítica (Roth, 2013: 69-78). Diríase que las dos últimas son resultado de la segunda, y la primera se encuentra aislada de las demás. Esto se debe a que el positivismo parte de la premisa según la cual la realidad es objetiva, real y medible," $y$ que puede ser entendida y explicada mediante la investigación empírica experimental" (Roth, 2013: 72). De allí que el discurso y la aplicación de las políticas públicas en la actualidad se centre en la medición de 
impactos, sin considerar el contexto ideológico de aplicación de dichas políticas. El institucionalismo, ligado a la teoría de la elección racional, se proyecta desde una premisa según la cual “los comportamientos responden a una lógica de reglas e incentivos, en vez de normas y valores. Dentro de las instituciones, los individuos intentan maximizar su utilidad. Las instituciones surgen para dar respuesta al problema de alcanzar cierto equilibrio en medio de un grupo de egoístas" (Losada y Casas, 2014: 180).

Asimismo, se parte de la noción según la cual la democracia liberal legitima el análisis y la implementación de políticas públicas desde una visión positivista y neoinstitucionalista, lo cual repercute negativamente en la resolución de problemas públicos respecto de las políticas con enfoque diferencial, pues ni la democracia liberal ni el neoinstitucionalismo piensan en función de las identidades colectivas y las posiciones de sujeto que estimulan el pluralismo jurídico, el pluralismo democrático y la interculturalidad. Por el contrario, la democracia liberal y el neoinstitucionalismo legitiman una mera aceptación nominal, no sustantiva, de las diversas poblaciones que en Colombia demandan la radicalización y la profundización de la democracia.

En ese orden de ideas, en lugar del binomio democracia liberal-neoinstitucionalismo, se propone el tándem democracia radical-construccionismo crítico para pensar y proyectar las políticas públicas con enfoque diferencial, pues a partir de esta posición teórica se repiensa la cultura como un espacio de expresión simbólica esencial para que los grupos subalternos cuestionen las relaciones de poder y asuman su realidad histórica y política, con el objetivo de que demandas como el fin de la economía extractivista, la participación política vinculante en decisiones sobre explotación de territorios y el fin de proyectos ideológicos que refuerzan la pobreza material de las comunidades (como las políticas sociales de corte neoasistencial y coyuntural, debido a la exigencia de recorte del gasto público social), pasen a ser elementos esenciales y transversales de los grupos minoritarios.

¿Por qué el construccionismo crítico? Porque este enfoque epistemológico parte de la base de que "la actividad investigativa está siempre orientada por valores y, en consecuencia, la objetividad y la búsqueda de la verdad son ilusorias". Y detalla Roth:

En particular, se busca legitimar una mayor participación de los ciudadanos para afianzar la democratización de los procesos de políticas públicas (...). De este modo, la teoría crítica desarrolla una explicación de las políticas públicas (...) como procesos que modifican la infraestructura comunicativa de la sociedad. Finalmente, con eso se condicionan los fundamentos normativos y las expectativas de la ciudadanía, lo que permite mantener y reproducir la dominación (...). De esta manera, la teoría crítica 
se propone develar las relaciones de poder y las manipulaciones de la vida cotidiana (Roth, 2014: 76; las cursivas son mías).

Es especialmente reveladora la noción de "develar las relaciones de poder", pues finalmente lo que se trata de plantear es cómo la democracia liberal y el neoinstitucionalismo legitiman unas relaciones de poder favorables a grupos hegemónicos que se complacen con enunciar en el discurso legal-institucional la inclusión de grupos minoritarios, pero en realidad, cuando se trata de escucharlos y de canalizar sus demandas, hacen uso de ese mismo aparato institucional para acallar las voces críticas del establecimiento.

\section{Anotaciones conceptuales sobre multiculturalidad e intercul- turalidad}

Multiculturalidad e interculturalidad son dos conceptos que se traslapan y que, casi siempre, se utilizan de manera indistinta en diferentes contextos. Antes de hablar de las diferencias entre ellos, determinadas por los sufijos multi-inter, es necesario plantear algunas aclaraciones conceptuales. Sin pretender ser exhaustivos con la definición de "cultura" -algo en esencia bastante problemático-, vale decir por lo pronto que la cultura, como teoría y práctica, es transversal a toda práctica social y que engloba todos los valores materiales e inmateriales que representan significados y sentidos para un grupo humano. Ello implica que la cultura es un campo de acción en el cual se libra la lucha por la representación simbólica, por lo cual se convierte en lugar estratégico de visibilización con el fin ya sea de perpetuar relaciones de poder o bien de modificar esas mismas relaciones de poder para otorgarle capacidad simbólica a un grupo humano.

A la co-existencia de estos múltiples grupos humanos en un territorio determinado, y a la inclusión nominal de dichos grupos en el orden político, la llamaremos multiculturalidad, según lo planteado por Sierra (2003). Por su parte, llamaremos interculturalidad, siguiendo a Walsh (2005), al proyecto epistemológico y político a través del cual se busca poner en cuestión las relaciones de poder entre el proyecto hegemónico montado en América Latina desde el proceso de colonización y los grupos sociales minoritarios que han sido históricamente marginados y hegemonizados por la estandarización del dispositivo Estado-nación.

El surgimiento del Estado-nación como estrategia de organización social, propia de la modernidad, trajo consigo la estandarización y la homogeneización de la vida 
social y política. En Europa, donde surgió el Estado-nación, la posibilidad de acumulación de capital por parte de la burguesía facilitó el orden social, pues nadie se vio aislado de los asuntos públicos. América Latina tuvo un proceso diferente. Según Badie, citado por Roth (2014: 25), la construcción del Estado-nación en América Latina fue mayoritariamente elitista, sin integrar a las poblaciones subalternas. ¿YY quiénes son los subalternizados?

En el contexto de una antropología crítica latinoamericana, la subalternidad se entiende, de acuerdo con Vásquez (2002):

Desde la resistencia étnica, que "se delimita por oposición al de dominación". Pero tal oposición no se afirma negando en bloque lo que excluye, constituyéndose en un concepto "otro", diferenciándose al asumirse como su contrario, sino que se expresa en tanto contradicción. Esto es, que acepta, y a la vez rechaza, la penetración de un "mundo de vida" extraño y dominante por medio de un proceso de síncresis que implica una interpretación gestada a partir de la ruptura y conservación de lo propio y del rechazo a la incorporación de lo ajeno. Y solamente se desarrolla desde una perspectiva que vislumbra en el horizonte el concepto de contrapoder.

La noción de minoría puede entenderse como un grupo social con particularidades culturales que los diferencia de otros, demográficamente inferior a otro u otros grupos sociales. Del mismo modo, las minorías pueden llegar a ser grupos subalternizados, en tanto en el territorio que residan no puedan ser libremente empleados sus valores, conductas, normas, códigos y comportamientos merced a la imposición de valores que ejerza la cultura dominante. Para los efectos del debate teórico propuesto en este artículo, los conceptos de subalternidad y decolonialidad pertenecen al mismo universo semántico, pues comparten el objetivo de desmontar las epistemologías coloniales que imponen formas unilaterales del ordenamiento jurídico, prolongan relaciones de poder que anulan el diálogo de saberes y eliminan de tajo cualquier simbología cercana a la interculturalidad y al pluralismo jurídico. En ese sentido, se entiende, siguiendo a Quijano (2000: 342), que si la colonialidad implica una taxonomía racial para determinar valores hegemónicos, la subalternidad es producto o consecuencia de dicha colonialidad:

La colonialidad es uno de los elementos constitutivos y específicos del patrón mundial de poder capitalista. Se funda en la imposición de una clasificación racial / étnica de la población del mundo como piedra angular de dicho patrón de poder, y opera 
en cada uno de los planos, ámbitos y dimensiones, materiales y subjetivas, de la existencia cotidiana y a escala social.

\section{Aspectos jurídicos de las políticas públicas con enfoque dife- rencial}

El enfoque diferencial, como estrategia de política pública, es producto de las particularidades políticas de Colombia, país que ha vivido durante los últimos 60 años un conflicto armado interno entre guerrillas revolucionarias de izquierda y las fuerzas del Estado, actores a los que hay que sumar el paramilitarismo y el narcotráfico. No se expondrán en este artículo las causas del conflicto, pero sí se presentarán algunas cifras, a modo de radiografía. Según el Centro Nacional de Memoria Histórica (2018), el conflicto armado ha dejado en Colombia 262197 muertos, de los cuales 215005 son civiles y 46813 son combatientes. A su vez, se atribuyen estas muertes de la siguiente formaः 94754 muertes a manos de los paramilitares, 35683 por parte de la guerrilla y 9804 se asignan a agentes del Estado.

De modo contrario a lo ocurrido en los países del Cono Sur, donde la violencia política ocurrió en el marco de dictaduras militares, en Colombia el baño de sangre se dio bajo la mirada de unas instituciones políticas democráticas estables, quizás las más estables del continente. Las instituciones de la democracia liberal colombiana funcionaron sin inmutarse ante la barbarie: había elecciones periódicas (aunque semicompetitivas, dado el pacto entre las elites del Frente Nacional), los medios de comunicación no eran abiertamente censurados (ni necesidad había, pues la gran prensa era propiedad de liberales y conservadores) y el capitalismo de libre mercado fluía sin cortapisas (incluso, con la existencia de ciertos visos de Estado de bienestar de corte cepalino).

En medio de la impertubabilidad institucional, la Colombia rural y periférica se sumía en los horrores de la guerra. Solo hasta hace pocos años, mediante diversas disposiones jurídicas - de las que ya se hablará-, se hicieron visibles las víctimas. En un país de historias oficiales, de discursos maniqueos de héroes y villanos, la puesta en escena de las víctimas mostró un discurso a contrapelo de la historia. Ya no es el relato de los vencedores sino el de los vencidos el que empieza a asomarse para narrar los sufrimientos hasta entonces escondidos. Se supo entonces que en Colombia han cargado con el mayor peso del dolor los afrodescendientes, los indígenas, las mujeres, la comunidad LGBTI, los campesinos, los niños y la población Rrom. Todos ellos grupos minoritarios y subalternizados. 
Conceptualmente, se entiende el enfoque diferencial como un proceso político en el que se afirman derechos identitarios. De manera operativa, el Comité Nacional de Reparación y Reconciliación (CNRR) (citado por Serrano, 20I4: 55) define el enfoque diferencial en el siguiente tenor:

Conjunto de pautas, medidas y acciones orientadas a grupos humanos con características particulares por razón de su diversidad cultural, edad, género, opción sexual y condición de discapacidad. En este sentido, se debe buscar que las diferentes perspectivas sean integrales al diseño, implementación, monitoreo y evaluación de las líneas estratégicas de acción que orientan el tratamiento, la atención y la reparación integral a víctimas.

Se trata de otorgar o reivindicar derechos jurídicos, políticos, sociales y culturales de poblaciones históricamente marginadas, como negritudes, indígenas, mujeres, campesinos, población LGBTI, raizales y palenqueros. Cuando se asegura que el enfoque diferencial afirma derechos identitarios, ello implica hablar en función de identidades colectivas que refuercen las posiciones de sujeto. Es decir, el enfoque diferencial es, a la larga, una apuesta política por el cuestionamiento de las relaciones de poder entre los grupos sujetos del enfoque diferencial y el poder hegemónico. Claramente, no era esa la intención del Estado. La intención era avalar una restitución de derechos desde la visión universalista de la democracia liberal. De hecho, el párrafo citado delata la asepsia propia del institucionalismo en la implementación de políticas. No se habla de identidades colectivas o modificaciones de relaciones de poder hegemónicas. Sin embargo, ese proceso de empoderamiento ha derivado en luchas sociales que cuestionan las articulaciones de poder hegemónicas.

Dicha reivindicación de derechos nace con la Constitución Política de I991 . La carta política de I886, vigente hasta entonces, encarnaba una visión de país excluyente, conservador y clerical. La Constitución del 9I, fruto del pacto entre diversas y disímiles fuerzas políticas, inaugura la visibilización de minorías.

El punto de partida en el país ha sido el reconocimiento hecho por la Constitución Política de I99r a la diversidad étnica y cultural, a la libertad e igualdad sin discriminación alguna, al libre desarrollo de la personalidad, a la libertad de conciencia, culto y pensamiento, a la libertad de asociación y a la protección especial de las mujeres de cualquier tipo de discriminación, los niños y adolescentes, las personas adultas mayores y las personas en situación de discapacidad. (Serrano Murcia, p. 45). 
Bajo el paraguas de la Carta Magna se agrupan diversas disposiciones jurídicas sobre políticas públicas con enfoque diferencial, entre las cuales se encuentran las siguientes:

\section{Cuadro i:}

Disposiciones jurídicas referentes a enfoques diferenciales en Colombia. Fuente: Serrano

(2014: 46).

\section{Principales Leyes en temas diferenciales en Colombia}

\section{Ley 21 de 1991. Ratificación del convenio 169 de la OIT - Derecho a la consulta previa.}

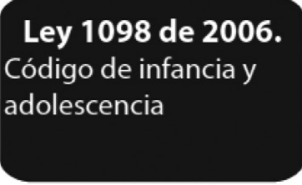

Ley 1381 de 2010.

Uso, preservación y fortalecimiento de las lenguas de los grupos étnicos.
Ley 70 de 1993. Reconocimiento de las Comunidades negrasy sus territorios en el país.
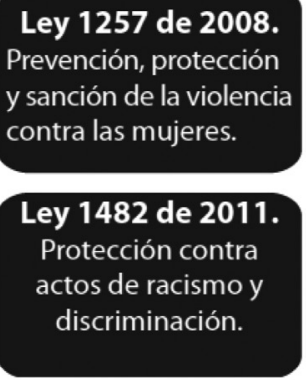

Ley 294 de 1996. Prevención y sanción de la violencia intrafamiliar.

Ley 1306 de 2009. Protección de personas con discapacidad mental.

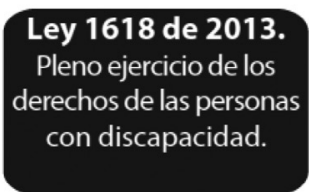

Sin embargo, es la Ley I448 de 2oII, de Víctimas y Restitución de Tierras, la que hace explícito el concepto de enfoque diferencial. Aprobada en el segundo año de gobierno del Presidente Juan Manuel Santos, dicha ley representó un punto de inflexión en el devenir histórico del conflicto armado en Colombia, por tres razones fundamentales. La primera es que se ubicó en el centro del conflicto a las víctimas. A partir de su aprobación, los relatos sobre la guerra en Colombia, en los que primaba la visión de los héroes (desde las guerras de independencia hasta la "guerra contra el terrorismo" de Álvaro Uribe, en la que se glorificaba la figura de las Fuerzas Militares). Ahora se proyectan desde las voces de las víctimas. La segunda es poner como elemento neurálgico del conflicto el problema de la tenencia de la tierra. Se ha planteado como causa fundamental y transversal de la violencia subversiva la inequidad en el acceso a tierras productivas. Y la tercera, que puede sonar a obviedad para el lector no colombiano, es que esta ley reconoce de manera explícita la existencia del conflicto armado en Colombia. La narrativa de sectores políticos de la extrema derecha, encarnada en Álvaro Uribe Vélez, presidente de Colombia entre 2002 y 2010, reducía la guerra a un enfrentamiento entre unos "terroristas" o "bandidos" 
alzados en armas y el Estado colombiano. Esta ley, al reconocer la existencia del conflicto armado, admite que las guerrillas son actores políticos alzados en armas e interlocutores válidos frente a las demandas que le puedan plantear al Estado colombiano. De aquí que, un año después, se iniciaran los diálogos entre el gobierno nacional y la guerrilla de las Farc, que desembocaron en el 2016 en su desaparición como grupo armado y su inserción en la vida civil, política e institucional del país.

Con respecto al enfoque diferencial, dicha ley expone lo siguiente:

ARTÍCULO I3: ENFOQUE DIFERENCIAL. El principio de enfoque diferencial reconoce que hay poblaciones con características particulares en razón de su edad, género, orientación sexual y situación de discapacidad. Por tal razón, las medidas de ayuda humanitaria, atención, asistencia y reparación integral que se establecen en la presente ley, contarán con dicho enfoque.

El Estado ofrecerá especiales garantías y medidas de protección a los grupos expuestos a mayor riesgo de las violaciones contempladas en el artículo $3^{\circ}$ de la presente ley tales como mujeres, jóvenes, niños y niñas, adultos mayores, personas en situación de discapacidad, campesinos, líderes sociales, miembros de organizaciones sindicales, defensores de Derechos Humanos y víctimas de desplazamiento forzado.

Para el efecto, en la ejecución y adopción por parte del gobierno nacional de políticas de asistencia y reparación en desarrollo de la presente ley, deberán adoptarse criterios diferenciales que respondan a las particularidades y grado de vulnerabilidad de cada uno de estos grupos poblacionales.

Igualmente, el Estado realizará esfuerzos encaminados a que las medidas de atención, asistencia y reparación contenidas en la presente ley contribuyan a la eliminación de los esquemas de discriminación y marginación que pudieron ser la causa de los hechos victimizantes.

El artículo 7 de la Constitución del 91, por su parte, explicita lo siguiente:"El Estado reconoce y protege la diversidad étnica y cultural de la nación colombiana”. En este punto cabe preguntarse si el enfoque diferencial como estrategia de política pública es eficaz para estimular la ciudadanía política y la democracia radical, una herramienta para la protección de derechos humanos, o una naturalización de la exclusión social y política. Si es esto último, equivaldría a afirmar que se nombra y se reconoce la diversidad, pero no se entrega el poder a los grupos diversos para dig- 
nificar sus demandas, pues estas van en contra de los intereses de las elites políticas y económicas. Para tratar de dilucidar el interrogante es necesario profundizar en la conceptualización en torno a la relación entre multiculturalidad, interculturalidad y democracia radical, pues en el desarrollo de estas categorías teóricas se devela la real intención respecto de las políticas con enfoque diferencial.

\section{Multiculturalismo, interculturalidad y enfoque diferencial}

Luis Ignacio Sierra (2003) plantea la discusión frente a la noción de multiculturalismo como legitimación del orden liberal excluyente. A través de dicha discusión se entiende la contradicción entre multiculturalidad e interculturalidad, y cómo el uso de uno u otro concepto implica, o una mera aceptación implícita de la coexistencia, o un replanteamiento de las relaciones de poder entre el proyecto hegemónico de la modernidad y grupos sociales minoritarios y hegemonizados.

Según lo afirmado por Sierra, y en coherencia frente a lo afirmado por Walsh, el multiculturalismo no es más que la enunciación de la existencia de grupos socioculturales con demandas políticas opuestas a los países cuyas formas de gobierno son democracias liberales. A su vez, estos gobiernos incluyen de iure en el ordenamiento político-jurídico las múltiples culturas existentes, pero su proyecto ideológico hegemónico las excluye de facto, pues sus demandas obstaculizan la visión desarrollista, propia de las tecno-democracias de mercado.

De esta forma, el afrocolombiano, el indígena, el palenquero, el hombre o la mujer cuya tendencia sexual se escapa del molde heteronormativo, han entendido que el discurso democrático-liberal-capitalista no es más que una estrategia de legitimación de su exclusión.

Para contextualizar mediante cifras la composición de los grupos étnicos en Colombia se presentan los siguientes números, basados en el censo del año 2005:

Cuadro 2:

División de los grupos culturales en Colombia.

\begin{tabular}{lcc}
\hline Categoría de autorreconocimiento & Número de personas & Porcentaje \\
\hline Raizal de San Andrés y Providencia & 30565 & $0.07 \%$ \\
\hline Palenquero de San Basilio & 7470 & $0.02 \%$ \\
\hline Negro(a) mulato afrocolombiano & 4273722 & $10.31 \%$ \\
\hline Indígena & $\mathrm{I} 392623$ & $3.43 \%$ \\
\hline
\end{tabular}




\begin{tabular}{lcc}
\hline Rrom & 4858 & $0.01 \%$ \\
\hline Subtotal & 5709238 & $13.84 \%$ \\
\hline Fuente: Departament
\end{tabular}

Fuente: Departamento Administrativo Nacional de Estadística (Dane), disponible en https://www.dane.gov.co/files/censo2005/etnia/sys/visibilidad_estadistica_etnicos.pdf

El hecho de que $13.84 \%$ de la población pertenezca a un grupo étnico es un desafío enorme en términos de diálogo de saberes interculturales. Ignorar a ese porcentaje de la población es una forma de imperialismo cultural. Asimismo, cabe anotar que la gran mayoría de indígenas y afrodescendientes están ubicados en la periferia del país. Regiones como Chocó, Cauca, Guainía, Vaupés, Nariño y San Andrés, al estar alejadas del centro hegemónico (región Andina), se cuentan entre las más carenciadas en cuanto a derechos civiles, políticos, sociales y culturales.

Pero, ¿cuál es la relación entre multiculturalismo, interculturalidad y enfoque diferencial? Se retoma la premisa con la que se inició este apartado. Sierra, citando a Estrach (2003: 75), afirma:

El capitalismo tardío multiculturalista tiene un síntoma, el racismo posmoderno contemporáneo, que muestra la condición propia del proyecto ideológico liberal-democrático. La diversidad cultural se acepta cuando actúa en beneficio de una particularidad especifica: la sociedad capitalista burguesa. En otras palabras, la forma de negación del individuo viene dada por la forma ideal de la ideología del capitalismo global, el multiculturalismo: una forma de racismo negada e invertida, que afirma tolerar la identidad del otro, concibiéndolo como identidad cerrada, frente a la cual el multiculturalista mantiene una posición de superioridad universal privilegiada (...) El multiculturalismo es así, fascismo marginalizador, políticamente correcto en sus enunciados y, en consecuencia, profundamente reaccionario en su práctica. (los subrayados son míos).

Por su parte, Catherine Walsh (2005: 4I) plantea los avatares políticos y epistémicos que acarrea la interculturalidad como proyecto ideológico que cuestiona las relaciones de poder contingentes, al decir de Mouffe. A partir de la pregunta, “¿qué implica pensar la interculturalidad como proyecto político y epistémico, el cual propone reformular el qué, el por qué y el para qué de los conocimientos?" Para responder este interrogante, se debe pensar lo político desde dos perspectivas. i) Más allá de los márgenes de la institucionalidad liberal, teniendo en cuenta que lo político es cualquier acción colectiva tendiente a mantener o a cuestionar relaciones de poder. ii) "Descolonizar el poder" implica pensar lo múltiple no solo como la coexistencia, sino como "intervención en los campos de marginalización y subalternización" (Walsh, 
2005ः 43). Así, penetrar dichos campos de subalternización tiene profundas implicaciones en la construcción de conocimientos y en la implementación de políticas, pues el campo epistémico desde el que se han construido las políticas públicas con enfoque diferencial ha sido el del liberalismo favorecedor de articulaciones de poder tendientes a favorecer los privilegios de los grupos hegemónicos. Asegura Walsh:

En el ámbito estatal la interculturalidad pierde su arista crítica y transformadora y asume más bien un sentido multi o pluriculturalista, entendido como la incorporación o inclusión de la diversidad étnica dentro de las estructuras sociales, políticas y de conocimiento existentes (...) La multiculturalidad (...) es más que todo descriptiva y se refiere a la multiplicidad de culturas que existen dentro de una sociedad sin que necesariamente tengan una relación entre ellas. Sus fundamentos conceptuales se encuentran en las bases del Estado liberal, de la noción del derecho individual y la supuesta igualdad (...) La interculturalidad es distinta, en cuanto se refiere a complejas relaciones, negociaciones e intercambios culturales de múltiple vía. Busca desarrollar una interrelación equitativa entre pueblos, personas, conocimientos y prácticas culturalmente diferentes; una interacción que parte del conflicto inherente a las asimetrías sociales, económicas, políticas y del poder (Walsh, 2005: 44-45).

A modo de ejercicio interpretativo, se expondrán algunos casos concretos que reflejan las contradicciones del Estado colombiano en torno a su discurso ideológico de "democracia participativa" y "multiculturalidad", que en realidad rechazan de plano el diálogo de saberes con grupos minoritarios y subalternizados.

Los proyectos extractivistas en Colombia reflejan la esquizofrenia jurídica del Estado colombiano en cuanto a, por un lado, la protección nominal de grupos minoritarios, y el desarrollismo que lo ha llevado a afectar en grado sumo el entorno en el cual viven grupos indígenas o afro, debido a los proyectos minero-energéticos de gran escala. A esto se le agrega otro elemento: la Constitución consagra las consultas populares como mecanismo de participación ciudadana (artículo I03) mediante el cual el pueblo -soberano- está habilitado para la toma de decisiones en cuanto al uso de sus territorios. De hecho, ha cobrado fuerza en los últimos años el uso de la consulta popular para frenar proyectos extractivistas. "De los II22 municipios de Colombia, en 92 se han hecho consultas en las que las comunidades consideran que la minería y el petróleo les han afectado el medioambiente o derechos fundamentales" (El Tiempo, 2018).

El conflicto social y la incompatibilidad política generados entre el mandato expresado por las ciudadanías y el modelo de desarrollo son evidentes: el pueblo 
es soberano sobre el territorio, pero la nación, como sujeto jurídico, es la dueña del subsuelo. Así, se hace patente la contradicción en los arreglos institucionales del país que, por un lado, nominalmente promueven la democracia participativa, pero por el otro mantienen una visión del desarrollo alejada de las cosmovisiones ya no solo de, por ejemplo, indígenas y afros, cuya noción del desarrollo no se sostiene en la generación de renta a costa de perjuicios ambientales, sino de los intereses de las identidades colectivas, que no desean la presencia de trasnacionales minero-energéticas debido a la depredación que estas suelen dejar en los territorios. Dietz (2018: III) plantea de la siguiente forma las potencialidades democráticas de mecanismos como la consulta popular:

Un integrante de Cosajuca, ${ }^{1}$ en Cajamarca, ${ }^{2}$ resume la función de la consulta para los actores de la protesta de la siguiente manera: La consulta popular es una herramienta, no es un fin. La votación es una cosa puntual, el mundo no empieza ahí y no termina ahí. Hay que meterle fuerza para que funcione. Lo fundamental es que la gente pueda participar. Nuestra apuesta es sensibilizar a la gente para que se apropie y se identifique con el proceso. La gente se convence cuando se siente parte de algo (entrevista realizada en Cajamarca el 8 de octubre de 2016). Las consultas populares tienen un potencial de participación elevado y fomentan, además, la participación de grupos marginados. En Piedras, ${ }^{3}$ fueron los propios habitantes quienes bloquearon el puente y posteriormente movilizaron la consulta en alianza con los productores de arroz. En Cajamarca, por su parte, fueron las organizaciones campesinas las que, junto a integrantes de organizaciones juveniles y con el apoyo del Comité Ambiental de Ibaguét $y$ varias organizaciones ambientales y de derechos humanos de todo el país, movilizaron la consulta (el subrayado es mío).

Por su lado, el abismo existente entre las disposiciones jurídicas y las realidades políticas excluyentes se evidencia también con la población LGBTi en Colombia, víctima de los avatares del conflicto armado y objeto de las políticas con enfoque diferencial. A pesar de que la Constitución del 9i no menciona de manera explícita a la población LGBTI como minoría que debe ser protegida de manera especial -

I Colectivo Socioambiental Juvenil de Cajamarca.

2 Municipio del departamento del Tolima, ubicado en el centro del país. Cajamarca es conocido como "la despensa agrícola del Tolima".

3 Municipio del departamento del Tolima.

4 Ciudad capital del departamento del Tolima. 
como sí lo hace con la población indígena y afro-, las dinámicas políticas actuales han provocado que se piense la cuestión LGBTI desde las identidades colectivas que reclaman no solo reconocimiento y garantía de derechos, sino el"desmonte del orden simbólico", al decir de Duque (20I8: 9I), que ha generado la subalternización de esta población. Dicho orden simbólico responde a la normalización de identidades de género y orientaciones de género puramente heteronormativas, que niegan la diversidad sexual y las corporalidades disidentes de lo hétero.

De acuerdo con Lozano y Prada, "lo trans es una categoría política que cuestiona el binarismo de género y la heterosexualidad obligatoria" (2012:75). Lo político aquí reside en el cuestionamiento de las relaciones de poder que han perpetuado un orden simbólico que normaliza las identidades y las orientaciones de género referidas a la heterosexualidad obligatoria y a los roles de género construidos históricamente desde valores hegemónicos, particularmente desde la familia y la religión como instituciones sociales.

La guerra como práctica política encarna un universo plagado de símbolos eminentemente masculinos, lo cual implica la negación de cualquier manifestación del género que se salga del molde heteronormativo. La virilidad como expresión de la masculinidad es el valor que guía a los guerreros, por lo cual un hombre "afeminado" no tiene cabida en la guerra. Peor aún, en Colombia, particularmente en sus regiones más apartadas, la población LGBTI ha sufrido como pocas los embates del conflicto, pues no se concibe a un hombre que modifique, ya sea de forma biológica o puramente exterior, su masculinidad.

Lozano y Prada (2010: 75-97) relatan cómo las personas trans han sufrido en Colombia merced al conflicto armado. Dado que "los grupos armados ejercen un fuerte control sobre las formas de llevar el cuerpo, así como sobre los comportamientos esperados, tanto de mujeres como de hombres, prestando especial atención al comportamiento sexual" (2010: 82), las personas que experimentan "tránsito por el género" son especialmente violentadas. Se referencian dos testimonios de personas trans (2010: 84-85) que han residido en municipios de Colombia en los que se ha vivido de forma más cruda el conflicto armado:

A mí me sacaron volada del barrio, porque como yo era travesti, como en el barrio en donde yo vivo eso es macabro, me sacaron y me dijeron que yo no podía vivir allá [...]. Pues, como yo iba a visitar a mi mamá a veces, un día me cogieron un poco de hombres de moto y me dijeron que yo no podía vivir en el barrio, que allá había muchos niños, que esto, que lo otro. Yo les dije "¿qué? ¿Por qué? si yo soy también del barrio", y me dijeron que me daban 24 horas para que me fuera (...) y entonces, 
como ellos tienen manipulado el barrio, yo mejor me voy antes de que me maten (entrevista con Xiomara).

De una u otra forma por eso me vine, porque tenía miedo de que me fueran a matar y fueron muchos a los que mataron, fueron muchos (...) es más, también por parte de algunos cabecillas de las $\operatorname{Auc}^{5}(. .$.$) . En un pueblo cercano, cogían a los gays, los$ abordaban y se los llevaban en camioneta, los amarraban, se los llevaban para una finca lejos (...) allá los encerraban como en un kiosco y ahí era‡ el uno mataba al otro, los colocaban a que se mataran entre sí (...) y fue una masacre hace años, donde este cabecilla, ese "Cadenas" ordenó la muerte de muchos gays (...) fue una masacre horrible y creo que sobrevivió uno solo (...). Entonces también eso era: el temor a que te fueran a coger $y$ te fueran a hacer lo mismo. Al que se cogían lo tiraban a un pozo donde había cocodrilos, porque tenían cría de cocodrilos, los tiraban a la poza de los cocodrilos o utilizaban la guadañadora (...). Claro, todo el mundo sabía que él fue el que había ordenado todo eso y de ahí todas las personas cogieron rumbo, cada una se fue con un rumbo diferente (entrevista con Alexa).

Tal y como lo mencionan las autoras -y tal y como se mencionó líneas arriba-, la Ley I448 hace referencia a la aplicación del enfoque diferencial, dirigida a las víctimas del conflicto armado en Colombia, de acuerdo con las características particulares de la población en razón de su edad, género, orientación sexual y situación de discapacidad (Lozano y Prada, 20I0: 90). Sin embargo, la noción de "género" se entiende en esta ley desde la perspectiva de mujer biológica, lo cual no responde a una conceptualización y a una práctica del género que esté más allá de los cánones heteronormativos. Desde la ley, género es igual a mujer en el sentido biológico y tradicionalmente aceptado de aquello que debe ser mujer, ignorando lo trans como categoría que entra también en una noción de género que expresa identidades y orientaciones, tanto físicas como erótico-afectivas, que cuestionan el binarismo de género.

Por esto, las disposiciones jurídicas referidas al enfoque diferencial se quedan muy cortas frente a las demandas identitarias de grupos subalternizados. Más aún, la ley no es capaz de "desmontar el orden simbólico" que refuerza relaciones de poder desiguales y que claramente atentan contra la reivindicación de derechos fundamentales. Las leyes, al ser también actos de habla performativos, de acuerdo con John Austin, son capaces de construir realidades que tienen dos caminos: o mantener el orden establecido, o modificarlo. De esta modificación y

5 Autodefensas Unidas de Colombia, conocidas de forma genérica como "paramilitares". 
deconstrucción del orden establecido surge la democracia radical como estrategia intercultural.

Lo político, al decir de Chantal Mouffe (2007: 16), alude a la construcción de "espacios de poder, conflicto y antagonismo". Y esta referencia a "lo político" -distinto a lo que la autora llama "la política" en referencia a las cuestiones de la mecánica institucional de las democracias- entraña una profunda crítica al liberalismo político que, como se ha afirmado en este artículo, despolitiza las luchas sociales en aras de una pretendida homogeneidad social. Dicha homogeneidad se encuentra íntimamente ligada al monismo jurídico, entendido según Gutiérrez como la "exclusividad del Estado en la creación del derecho, y que el único derecho debería ser el creado por el soberano" (Gutiérrez, 20II: 86). Esta noción positiva y central del derecho riñe con la construcción de dispositivos jurídicos que respondan a las demandas políticas de los diversos grupos minoritarios y subalternizados que residen en un territorio.

Según Mouffe (1999: 38), "la tarea de la democracia radical es en verdad la de profundizar la revolución democrática y conectar las distintas luchas democráticas. Esa tarea requiere la creación de nuevas posiciones subjetivas que permitan la articulación común de, por ejemplo, antirracismo, antisexismo y anticapitalismo". Mouffe entiende la democracia radical como toda acción deconstructiva y antiesencialista destinada a la modificación de las relaciones de poder que subalternizan a las minorías y obstaculizan el diálogo intercultural.

Dicha noción de democracia radical está íntimamente ligada con el pluralismo jurídico. Partiendo de la interculturalidad, las políticas públicas con enfoque diferencial deben, entonces, responder a los criterios del pluralismo jurídico. Tal y como lo afirma Gutiérrez, "Colombia no es una sociedad global con valores universales, sino un conjunto de culturas con valores específicos. En otras palabras, diferentes contextos, cosmovisiones y sistemas económicos, sociales y jurídicos" (Gutiérrez, 20II: 87). Dicha diversidad se ve reflejada, por ejemplo, en el caso de los pueblos indígenas del $\mathrm{Cauca}^{6}$ y los títulos de propiedad colectiva, en los cuales se les otorga prelación en la explotación de recursos mineros, de acuerdo con Caro (2014: 258).

A partir de la Ley 2255 (o Código Minero), se creó la figura de Zona Minera Étnica (zMI). Se especifica que dichas zonas:

Cuentan con una regulación especial y una serie de medidas que determinan procedimientos específicos en relación con quiénes, dónde y cómo se explotan minerales en territorios indígenas. Justamente, la disposición expresada en el artículo I30 de

6 Departamento ubicado en el suroccidente de Colombia. 
este código faculta a las autoridades indígenas para señalar y restringir los lugares de exploración y explotación minera dentro de las zMi por razones culturales, espirituales y de uso (Caro, 2014: 258).

¿Estas disposiciones jurídicas responden a un diálogo intercultural?

En la cuestión de los Nasa, pueblo indígena del departamento del Cauca, se entrecruzan dos males: el conflicto armado y el despojo de tierras, que data desde los tiempos de la colonia y que posteriormente fue impulsado por el Estado con el fin de brindarle a las grandes empresas los terrenos para el monocultivo de caña de azúcar.

Sobre la cuestión de la asignación de las ZMI se ciernen numerosas problemáticas, ligadas al uso "de sustancias tóxicas, como el mercurio y el cianuro, para la captación del oro". Esto ha ocasionado lo que se puede denominar como un proceso de mercantilización y cosificación de la minería artesanal entre los indígenas del Cauca, pues estas prácticas han ocasionado impactos culturales que acarrean la llegada de nuevos modelos de vida a las comunidades, la emergencia de derechos extractivos individuales y la agudización del conflicto armado" (Caro, 20I4: 27I), además de los graves perjuicios ambientales.

El cuidado del ambiente es un elemento central en la cosmovisión Nasa, que define así la relación entre vida y territorio:

Los Nasa conciben la naturaleza como la MADRE y específicamente la denominan Yat, "casa", que es Tierra, la Tierra y sus bienes es entendida como el cuerpo de la comunidad, es decir que es la comunidad misma. Hay una continuidad entre los Nasas y la Tierra, que además es madre y origen cósmico y cosmogónico (Caro, 20I4: 264-265).

Claramente, el despliegue de la cosmovisión Nasa es difícilmente aplicable y replicable si la constante es el despojo y el uso extractivo de sus recursos. Así, se evidencia que "entre las regiones del norte del Cauca, centro del Valle del Cauca y sur de Risaralda, existen 225560 hectáreas destinadas a la extracción de caña de azúcar" (Semana Rural, 2017).Y todo este territorio es aprovechado por los grandes ingenios azucareros para la producción de biocombustibles, cuya cifra llega, aproximadamente, a I 200000 litros por día (Semana Rural, 2017).

Según declaraciones dadas por el pueblo Nasa,"el fin de la liberación no es tomar los medios de producción y apropiarse de ellos. Se trata de cambiar el modelo económico de la tierra y garantizar el alimento a las comunidades indígenas de la región" (Semana Rural, 2017). Se subraya la expresión "cambio en el modelo económico 
de la tierra" para denotar que este principio, indispensable para la economía del pueblo Nasa, resulta una herejía para la visión desarrollista del Estado, desde la cual la tierra debe responder a criterios de productividad y renta, que solo se logran si intervienen las grandes empresas. Se refleja, una vez más, la esquizofrenia del Estado colombiano con respecto a la protección de las minorías: por un lado, otorga mediante dispositivos jurídicos las Zonas Mineras Étnicas, pero, por el otro, buena parte del territorio está otorgado a grandes empresas productoras de caña de azúcar.

\section{Conclusiones}

Se ha mostrado cómo la aplicación de las políticas públicas con enfoque diferencial en Colombia no responde a los criterios de interculturalidad que demandan las poblaciones minoritarias y subalternizadas. Por ello, se enfatizó en la necesidad de la implementación de políticas públicas desde un enfoque epistemológico crítico-construccionista, desde el que se contemplen los valores e ideologías de las poblaciones objeto de dichas políticas, y partir del pluralismo jurídico como principio fundamental de la interculturalidad.

Conceptualmente, la cuestión de los grupos subalternos demanda pensar su accionar político desde aquello que Mouffe denomina "identidades colectivas", las cuales deben estar ligadas a la construcción de una democracia radical y, desde allí, implementar políticas públicas con enfoque diferencial que partan del diálogo intercultural.

La articulación de intereses y demandas colectivas de grupos sociales heterogéneos, que entienden el orden político como algo contingente y, por tanto, perecedero y susceptible de modificación, debe ser el baricentro de la implementación de políticas con enfoque diferencial, con el fin de no solo reivindicar y garantizar el acceso a derechos fundamentales; en la práctica, lo que se espera para que lo anterior se lleve a cabo es la unión de los grupos subalternizados (afros, indígenas, LGBTI, campesinos) con el fin de articular demandas que partan de la interculturalidad, no de la aceptación nominal de su existencia en el territorio. Demandas que no son más que la puesta en práctica de la democracia radical.

Esto conlleva a articular la lucha de los movimientos sociales a través de lo que Mouffe llama "cadena de equivalencias". Esto es, juntar las luchas de los subalternizados que conforman la escena del pluralismo radical, con el fin de que la izquierda instaure "una voluntad colectiva de todas las fuerzas democráticas para impulsar una radicalización de la democracia e instalar una nueva hegemonía" (Mouffe, 2013: 246). 
Pero no se trata de nombrar para después excluir, como lo hacen el multiculturalismo y la democracia liberal. Se trata de establecer una interlocución horizontal entre el Estado y las múltiples culturas y demandas políticas para canalizar demandas del pluralismo y, eventualmente, modificar el orden hegemónico, siempre contingente.

La posibilidad real de generar un orden político otro, en el que se piense el desarrollo desde miradas alternativas, protectoras del medio ambiente y de la diversidad y alejadas de las subjetividades colonizadas por el consumismo, es posible si las políticas públicas asumen a los grupos minoritarios como sujetos epistémicos, mediante articulaciones políticas que respondan a las voces que claman un orden hegemónico diferente.

\section{Bibliografía}

Caro Galvis, C.

2014 "Minería en el norte del Cauca indígena. Prácticas territoriales y transformaciones socioespaciales en los resguardos indígenas nasa del municipio del municipio de Santander de Quilichao, Cauca, Colombia”, en B. Gobel y A. Ulloa (eds.), Extractivismo minero en Colombia y América Latina, Bogotá, Universidad Nacional de Colombia.

Colombia. Congreso de la República

Marzo de 2012 Ley I448 de 20II, Por la cual se dictan medidas de atención, asistencia y reparación integral a las víctimas del conflicto armado interno y se dictan otras disposiciones. Recuperado de http://www. unidadvictimas.gov.co/es/ley-I448-de-20II/13653

Centro Nacional de Memoria Histórica

2018, o2 de Agosto 262197 muertos dejó el conflicto armado. Recuperado de http://www.centrodememoriahistorica.gov.co/noticias/noticias-cmh/262-197-muertos-dejo-el-conflicto-armado (consulta: $06 / 09 / 2018)$.

Departamento Administrativo Nacional de Estadística. (s.f)

07/09/29018 La visibilización estadística de los grupos étnicos colombianos. Recuperado de https://www.dane.gov.co/files/censo2005/etnia/sys/visibilidad_estadistica_etnicos.pdf 
Dietz, K.

2018 "Consultas populares en Colombia: Condiciones de su realización y significados políticos. El caso de La Colosa”, Colombia Internacional, 93, pp.93-II7. DoI* https://dx.doi.org/IO.7440/colombiaint93.2018.04.

Duque, $C$.

2010 "Judith Butler y la teoría de la performatividad de género", Revista de Educación y Pensamiento, I7, pp. 85-95.

El Tiempo

2018 Arranca en la Corte debate clave para minería y petróleo, in de abril. Recuperado de https://www.eltiempo.com/justicia/cortes/arranca-en-la-corte-debate-clave-para-mineria-y-petroleo-sobre-consultas-populares-204000 (consulta $08 / 05 / 2018$ ).

Gutiérrez, M.

201 "Pluralismo jurídico y cultural en Colombia”, Revista Derecho del Estado, 26, pp. 85-I05.

Losada, R. y A. Casas

2010 Enfoques para el análisis político. Historia, epistemología y perspectivas de la ciencia politica, Bogotá, Pontificia Universidad Javeriana.

Lozano Ruiz, L. y N. Prada

2012 "Mujeres trans y conflicto armado en Colombia: afectaciones específicas y retos para la implementación de la ley de víctimas", en Identidades, enfoque diferencial y construcción de paz, Bogotá, Universidad Jorge Tadeo Lozano.

Mouffe, C.

1999 El retorno de lo político. Comunidad, ciudadanía, pluralismo, democracia radical, Barcelona, Paidós.

Mouffe, C.

2007 En torno a lo político, Buenos Aires, Fondo de Cultura Económica.

Mouffe, C.

2013 "Antagonismo y hegemonía. La democracia radical contra el consenso neoliberal", en Pensar desde la izquierda, mapa del pensamiento crítico para un tiempo de crisis, Madrid, Errata Naturae, pp. 24I-257.

Quijano, A.

2000 "Colonialidad del poder y clasificación social", Journal of World-Systems Research, 6(2), pp. 342-386. 
Roth Deubel, A.

2014 Politicas públicas: formulación, implementación y evaluación, Bogotá, Ediciones Aurora.

Semana Rural

2017 La lucha del pueblo Nasa por la liberación de sus tierras, I de octubre. Recuperado de https://semanarural.com/web/articulo/la-lucha-delpueblo-nasa-por-la-liberacion-de-sus-tierras-en-el-cauca/24I. (consulta: 16/06/2019).

Serrano Murcia, A.

2014 "Perspectivas diferenciales en la justicia transicional en Colombia: avances y retos", en Desafíos para la Reintegración, Enfoques de Género, Edad y Etnia, Centro Nacional de Memoria Histórica-Dirección de Acuerdos de la Verdad, pp. 37-73. Bogotá, Imprenta Nacional.

Sierra, L.

2003 "Globalización, multiculturalismo y comunicación. Paradojas y debates", Diálogos de la Comunicación, 66, pp. 69-80.

Vázquez, $\mathrm{H}$.

2002 "Procesos identitarios, 'minorías' étnicas y etnicidad: los mapuches de la República Argentina", Amnis, 2, DoI* 10.4000/amnis.167.

Walsh, C.

2005 "Interculturalidad, conocimientos y decolonialidad", Signo y Pensamiento, 24(46), pp. 39-50.

Andrés Francisco Olivar Rojas

Es Magíster en Estudios Políticos por la Pontificia Universidad Javeriana de Bogotá. También es Comunicador Social-Periodista por la Corporación Universitaria Minuto de Dios-uniminuto, Sede Cundinamarca, Centro Regional Girardot. Actualmente se desempeña como profesor de la Facultad de Ciencias Humanas y Sociales, en el Programa de Trabajo Social de la Corporación Universitaria Minuto de Dios-uniminuto, Sede Cundinamarca, Centro Regional Girardot. Su área de especialidad es la teoría política. Entre sus publicaciones recientes se pueden mencionar:"El Estado en el conflicto armado colombiano: entre la modernidad irresuelta, los retos del posacuerdo y de la globalización", Revista Prospectiva, Universidad del Valle, Colombia, 20I7; "El terrorismo como palabra y acción: Complejizar el objeto para entender las dinámicas de los conflictos contemporáneos", Revista Escribanía, Universidad de Manizales, Colombia, 20I6; "Contingencia vs. transversalidad, o 
sobre la debilidad del Estado de Derecho", Revista Escribanía, Universidad de Manizales, Colombia, 2015.

Citar como: Andrés Francisco Olivar Rojas (2020),"Políticas públicas y enfoques diferenciales: aproximaciones desde la interculturalidad y la democracia radical", Iztapalapa. Revista de Ciencias Sociales y Humanidades, núm. 88, año 4I, enero-junio de 20IO, ISSN: 2007-9176; pp. I39-I62. Disponible en $<$ http://revistaiztapalapa.izt.uam.mx/index.php/izt/issue/archive >. 